\title{
Bireysel ve İlişkisel Bağlamda Algılanan Partner Duyarlığı: Derleme Çalışması
}

\author{
Fulya Kirımer-Aydınl1 ${ }^{1}$ \\ Anadolu Üniversitesi
}

\author{
Nebi Sümer ${ }^{2}$ \\ Sabanc1 Üniversitesi
}

\begin{abstract}
Özet
Algılanan partner duyarlığı (APD) kişinin ihtiyaç duyduğu anlarda romantik partnerinin onu ne kadar anladığını, ona ne kadar değer verdiğini ve ilgi gösterdiğini değerlendirdiği bir süreçtir (Reis ve Shaver, 1988). APD'nin hem bireysel hem de yakın ilişkiler bakımından önemli sonuçları vardır. Yakın ilişkilerle ilgili birçok yapı belirli düzeylerde APD'yi kapsar. Birçok kuramsal yaklaşım (örn., bağlanma kuramı, öz-belirleme kuramı) da APD'nin kişisel ve ilişkisel süreçlerdeki önemine vurgu yapmaktadır. Bu nedenle APD ile ilgili çalışmalar özellikle son on yılda artan bir ivmeyle ön plana çıkmıştır. Bu yazıda APD’nin romantik ilişki yazınındaki yerini inceleyen mevcut çalışmalar derlenmiştir. Bu kapsamda, önce APD'nin psikolojik ve fiziksel esenlik, benlik düzenleme süreçleri ve ilişkisel işleyiş üzerindeki olumlu katkılarını saptayan çok sayıda çalışmanın bulguları özetlenmiştir. Sonra, APD’nin olası yordayıcıları ve romantik ilişkilerdeki rolünü açıklayan güncel modelleri sunulmuştur. Son olarak, bulguların kritik doğurgularına ilişkin değerlendirmelere ve gelecek çalışmalara yönelik bazı önerilere yer verilmiştir.
\end{abstract}

Anahtar kelimeler: Algılanan partner duyarlığı, esenlik, benlik düzenleme, ilişkisel işleyiş, romantik ilişkiler

\begin{abstract}
Perceived partner responsiveness (PPR) reflects the evaluation of a romantic partner's understanding, validating, and caring for in times of one's need (Reis \& Shaver, 1988). PPR has critical implications for both the individual and relational outcomes. A number of processes and structures in close relationships include PPR at different levels. Several theoretical approaches (e.g., attachment theory, self-determination theory) support the role of PPR in personal and relational processes. Thus, this paper presents a literature review on the-state-of-the-art on the role of PPR in romantic relationships. In this context, abundant studies documenting the effect of PPR on both psychological and physical well-being, self-regulation processes, and relationship functioning are examined. Moreover, studies examining the potential predictors of PPR and proposed recent conceptual models explaining the role of PPR in romantic relationships are presented. Finally, considering the implications of PPR, some recommendations are suggested for further studies.
\end{abstract}

Keywords: Perceived partner responsiveness, well-being, self-regulation, relationship functioning, romantic relationships

Yazışma Adresi: ${ }^{1}$ Arş. Gör. Dr. Fulya Kırımer-Aydınlı, Anadolu Üniversitesi, Edebiyat Fakültesi, Psikoloji Bölümü, 26470, Tepebaş1 / Eskişehir, fulyakirimer@anadolu.edu.tr, ORC-ID: 0000-0003-1125-4957

2Prof. Dr., Sabancı Üniversitesi, Sanat ve Sosyal Bilimler Fakültesi, Tuzla / İstanbul, nebi.sumer@sabanciuniv.edu, ORC-ID: 0000-0002-74604515

Gönderim Tarihi: 31.07.2019

Kabul Tarihi: 01.12.2020 
Bir yakın ilişkide ne kadar sevildiğimizi, değer verildiğimizi partnerimizin (sevgilimizin, eşimizin) bize ne oranda duyarlı olduğuna bakarak anlarız. Bu nedenle, algılanan partner duyarlığı (APD; perceived partner responsiveness) kişinin psikolojik esenliği ve yakın ilişkileri için en işlevsel faktörlerden biridir. Partnerlerin ihtiyaç duyulduğunda duyarlılık göstermesi beklenir. Beklentilerin karşılanıp karşılanmaması ise kişinin partner duyarlığını nasıl algıladığına göre şekillenir. Partner duyarlığının olumlu veya olumsuz algılanma düzeyi de bireysel ve ilişkisel bağlamdaki çıktıları (örn., psikolojik esenlik, ilişki doyumu) belirler. Bir ilişkide her iki partnerin de anlaşılmak, değer görmek ve önemsenmek istemesi nedeniyle APD ikili ve karşılıklı işleyen bir süreçtir. Bu nedenle, yakın ilişkilerde hem bireysel hem de ilişkisel sonuçların anlaşılabilmesi ve ilișkinin geleceğine dönük tahminler yapılabilmesi için APD sürecinin her iki taraf açısından da incelenmesi ve yorumlanması önem taşımaktadır. Bu makalenin amacı, APD'nin kişisel bağlamda ve romantik ilişkilerdeki rolü hakkında kapsamlı bir yazın taraması sunmaktır. İlk kısımda APD'nin nitelikleri ve APD'yi ölçme yöntemlerine, ikinci kısımda APD'nin kişisel ve kişilerarası süreçlerdeki yerini inceleyen çalışmalara ve şimdiye kadar öne sürülen APD modellerine yer verilecektir. ${ }^{1}$ Son olarak konuyla ilgili gelecek çalışmalara ilişkin öneriler sunulacaktır.

\section{APD'nin Tanımı ve Önemi}

APD aktörün ${ }^{2}$ ihtiyaç duyduğunda partnerinin sergilediği davranışları duyarlı veya duyarsız olarak değerlendirdiği bir süreçtir. Değerlendirme sürecinde aktör üç ana faktörü; anlaşılma hissi, değer verilme algısı ve ilgi görme algısını göz önünde bulundurur. Anlaşılma partnerin aktörün kendine özgü özelliklerinin, duygu ve düşüncelerinin farkında olup olmaması ile tanımlanırken, değer verilme partnerin aktörün bakış açısına, arzu ve hedeflerine sayg1 gösterip göstermemesine karşılık gelmektedir. İlgi görme ise partnerin sevgi, ilgi, şefkat ve duygusal destek gösterip göstermemesi, kişisel ve psikolojik ihtiyaçların karşılanmasında partnerin yardımcı olup olmaması olarak tanımlanmaktadır (Reis, 2007; Reis, Clark ve Holmes, 2004; Reis ve Shaver, 1988). Bireylerin her bir ilişkide ve hatta aynı ilişki içinde gösterdikleri duyarlık düzeyleri farklılaşabilir. Bu da duyarlığın partnere özgü bir süreç olduğunu gösterir (Lemay, Clark ve Feeney, 2007).
APD'nin üç faktörü olan anlaşılma, değer verilme ve ilgi görme algıları ilk kez Reis ve Shaver'in (1988) yakınlık süreci modelinde sistematik olarak tanımlanmıştır (bkz. Şekil 1). Bu modele göre yakınlığın oluşabilmesi iki unsura bağlıdır. Biri aktörün kendini açmas1 ya da ifade etmesi (self-disclosure), diğeri ise buna karşılık olarak gösterilen partner duyarlılığının algılanmasıdır. Aktör herhangi bir kişisel yaşantısını veya duygusunu partneriyle paylaştıktan sonra partner duygusal veya davranışsal bir tepkide bulunur. Aktörün kendine özgü güdüsel özellikleri, ihtiyaçları, amaçları ve korkuları hem kendisini nasıl ifade edeceğini hem de partnerin kendisine yönelik davranışlarını nasıl algılayacağını belirler. Partnerin güdü, ihtiyaç, amaç ve korkuları ise ifade edilen durumu nasıl yorumladığını ve bu duruma nasıl tepki verdiğini belirler. Partnerin tepkileri aktörün anlaşılma, değer verilme ve ilgi görme algıları (APD) temel alınarak değerlendirilir. Partnerin duyarlı olarak algılanmasının ilişkide yakınlık hissi ile sonuçlanması beklenir. Yakınlık karşılıklı bir süreç olduğu için ilişki içinde çiftler kimi zaman aktör kimi zaman partner rolünü üstlenirler. Dolayısıyla, karşılıklı APD arttıkça, hissedilen karşılıklı yakınlık derecesi de artar (Reis ve Shaver, 1988). Yakınlık, bir ilişkideki süreklilik, doyum ve uyum için gerekli bir unsurdur. Kendini açma ve duyarlık doğrudan yakınlık sürecini etkilediğinden, bu bileşenlerden birinin eksikliği yakınlık hissinin azalmasına neden olabilir. Bu da sonuçta ilişkide doyumsuzluğa, hatta ayrılığa yol açabilir (Laurenceau, Barrett ve Rovine, 2005). Bu nedenle, ilişkide APD'nin rolünü anlamak, yakın ilişki kurma ve ilişki içinde yaşanan sorunları çözme konularına açıklık getirmek bakımından önemlidir.

APD’yi daha iyi anlamak için akla gelebilecek birkaç soruyu cevaplamak gerekir. İlk olarak, gözle görünen destek mi yoksa görünmeyen (algılanan) destek mi APD'ye daha çok katkı sağlar? İlgili yazında bu konunda çelişkili bulgular bulunmaktadır. Bazı çalışmalar gözle görünmeyen desteğin diğerine göre kişinin huzuru ve olumlu hisleriyle daha fazla ilişkili olduğunu göstermiştir. Gözle görünen desteğin benlik üzerindeki olumsuz etkileri azalan özgüven ve artan strese bağlanmıştır (örn., Bolger, Zuckerman ve Kessler, 2000). Bunun aksine, APD'nin her durumda ve desteğin gösterilme şeklinden bağımsız olarak önemli olduğu da bazı çalışmalarda gösterilmiştir (örn., Maisel ve Gable, 2009). Benzer şekilde, kişiler partnerlerini duyarlı algıladıkları durumda

1 Bu çalışmada, konuya ilişkin öncü makalelerin yanı sıra Scopus veri tabanından erişilen ve "algılanan partner duyarlığı" söz öbeğini içeren ilgili yazına ait 51 makalenin bulgularına yer verilmiştir.

2 Dolaylı bir anlatım olması nedeniyle zaman zaman davranıșı gösteren ve davranıșı değerlendiren kișileri tanımlarken karıșıklık yașanabilmektedir İlgili yazında bu konuda farklı kavramlar kullanılmaktadır. Mevcut çalışmalarda davranışı değerlendiren kişi için "algılayan", "aktör", "muhatap" gibi sözcükler kullanılırken, davranışı gösteren kişi için "destek veren", "partner", "cevap veren” gibi sözcükler kullanılmıştır. Karışıklığı önlemek adına bu derleme makalesinde "aktör" sözcüğü partner duyarlığını değerlendiren ve algılayan kiși için, "partner" sözcüğü ise duyarlığı göstermesi beklenen kişi için kullanılmıştır. 


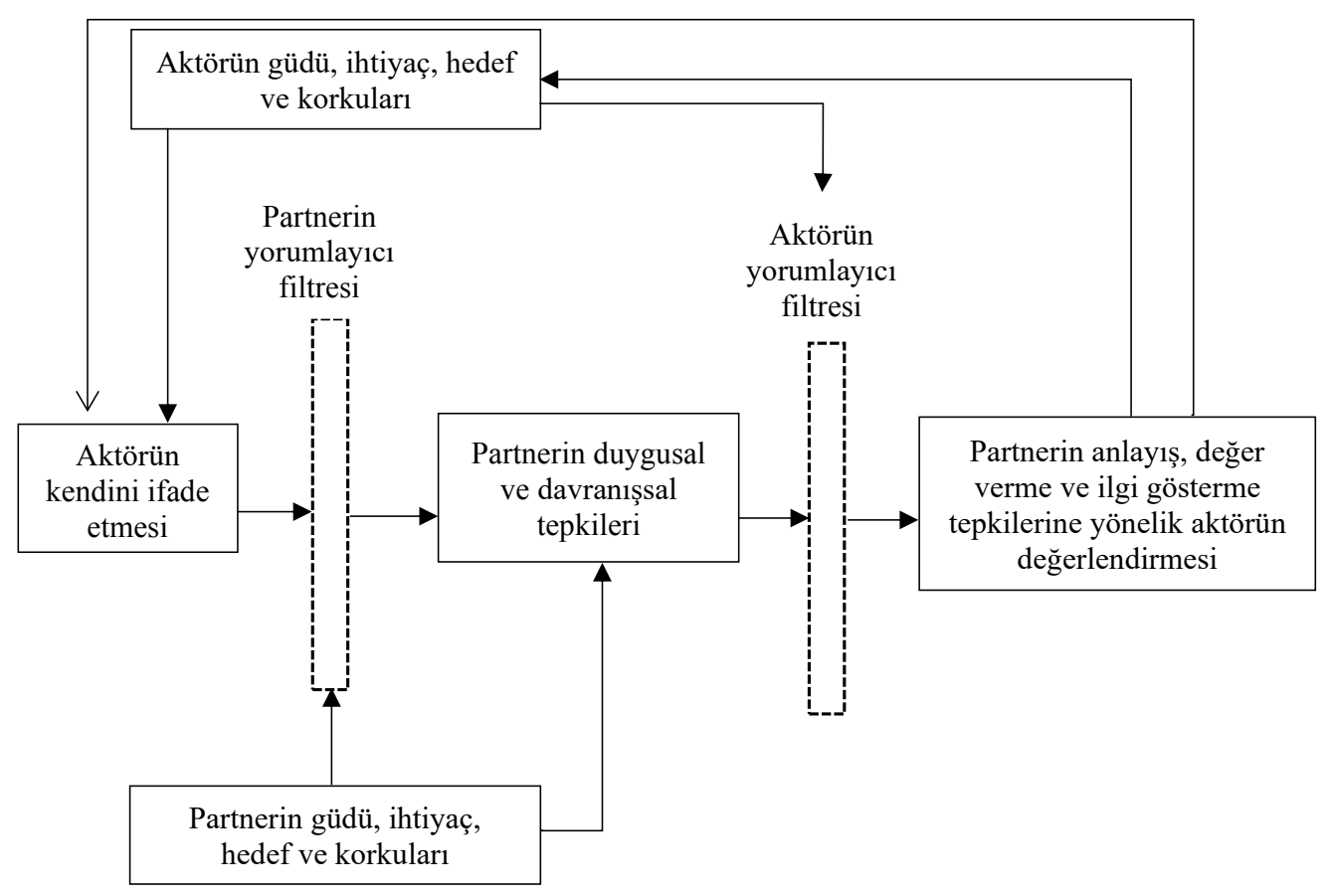

Şekil 1. Yakınlık Süreci Modeli (Reis ve Shaver, 1988).

hem görünen hem görünmeyen desteğin kişilerin duygu durumunu olumlu yönde yordadığı bulunmuştur. Partnerlerin duyarsız algılandığı durumda ise kişilerin ruh halini yordamada ne görünen ne de görünmeyen desteğin yeterli olduğu gösterilmiştir (Reis, Clark ve Holmes, 2004). Bu bulgular APD'nin farklı destek türlerinin kişisel ve ilişkisel çıktılardaki rolünü açıklamada önemli bir düzenleyici (moderatör) değişken olduğuna işaret etmektedir. İkinci soru, APD ve algilanan duygusal destek birbirinden farklı mıdır? Genellikle kişiler sadece duygusal desteğe değil, aynı zamanda yakınlık görmeye ve önemsenmeye de ihtiyaç duyarlar. Dolayısıyla, APD'nin algılanan duygusal destekten daha kapsayıcı bir yapı olduğunu söylemek mümkündür. Yine de bu farkın bilimsel araştırmalar ile desteklenmesi gerekmektedir (Selçuk ve Ong, 2013). Üçüncü soru, algılanan partner duyarlığg1 kişisel ve ilişkisel çıktıları açıklamada gerçek partner duyarlığından neden daha önemlidir? Gerçek partner davranışları partnerin sağladığı ve beyan ettiği davranıșlardır. Partner ve ilişski hakkında değerlendirme yapabilmek için hem algılanan hem de gerçek davranışları incelemek gerekse de gerçek davranışların aktörün çıktıları üzerindeki etkisi aktörün bu davranışları nasıl yorumladığına bağlıdır. Bu nedenle, ilişkisel çıktıları yordamada APD, yani aktörün desteklendiğini hissetmesi, gerçekten desteklenmesinden daha önemli bir rol oynar (Reis, 2007).
Dördüncü soru, duyarlık ve sosyal destek aynı örüntüyü mü işaret eder? Kuramsal bakımdan bu iki yapı birbirinden farklıdır. Sosyal destek yardım ve bilgi sağlamayı içerirken psikolojik hassasiyet ve aktörün ihtiyaçlarına dikkat göstermek duyarlığın önkoşullarıdır. İki yapı arasındaki farkı daha açık ortaya koymak, desteği faydalı hale getirenin hangi mekanizma olduğunu anlamamıza yardımcı olacaktır (Canevello ve Crocker, 2010). Sosyal destek, içinde algılanan destek (genel olarak desteğin varlığı), algılanan duyarlık (duruma özgü desteğin varlığ1) ve verilen (asıl) desteği içeren daha kapsayıc1 bir kavramdir (Tomlinson, Feeney ve Van Vleet, 2016). Buna bağlı olarak, APD sosyal desteğin ana unsurlarından biridir. Verilen destek, ancak destek alanın ihtiyaçlarını karşıladığı zaman tatmin edici olduğundan partner duyarlığının öznel değerlendirmesi bu süreçte önemli bir rol oynar. Bu nedenle desteğin etkisini tam olarak anlayabilmek için APD'yi değerlendirmelere katmak gerekir (Collins ve Feeney, 2000; Maisel ve Gable, 2009; Tomlinson, Feeney ve Van Vleet, 2016).

Özetle, APD ile ilgili çalışmalar incelenirken yazındaki diğer benzer kavramlardan fark1 dikkatle gözetilmeli ve duyarlığın kişisel ve ilişkisel çıktılar üzerindeki rolünü saptayabilmek için APD gerçek davranıștan bağımsız olarak ölçülmelidir. Bir sonraki kısımda APD'yi ölçme yöntemlerine ilişkin çalışmalar özetlenmiştir. 


\section{APD'nin Ölçümü}

APD'yi değerlendirme yöntemleri mikro ve makro düzey yöntemler olarak gruplandirılabilir. Mikro düzey değerlendirmede, partnerin sözel ve sözel olmayan ifadeleri, ve duyarlık davranışları (örn., sözel olmayan davranışlar, ses tonu, bağırma, göz kontağı vb.) hakkında çıkarım yapmak amacıyla kodlanmaktadır (Maisel, Gable ve Strachman, 2008). Makro düzey değerlendirme ise aktörün veya bir gözlemcinin partnerin anlama, değer verme ve ilgi gösterme davranışlarını değerlendirmesine dayanmaktadır. Aktör veya gözlemci değerlendirme s1rasında yine partnerin mikro düzeydeki sözel veya sözel olmayan ifade ve davranışlarını saptayarak bir yargıda bulunduğu için çalışmanın amacına bağlı olarak kapsay1cılık açısından sadece makro düzeyde ölçüm yapmak yeterli olabilir (Winczewski, Bowen ve Collins, 2016). APD birkaç çalışmada aktöre doğrudan partnerin duyarlı olup olmadığı sorularak ölçülmüş olsa da (örn. Debrot, Cook, Perrez ve Horn, 2012), genellikle aktör dolaylı olarak ve birkaç madde ile partnerin anlama, değer verme ve ilgi gösterme süreçlerini derecelendirmektedir. Reis ve Shaver'in (1988) öncü makalesinin 1şı̆̆ında, son çalışmalarda APD'nin doğrudan üç ana unsurunu ölçmeye yönelik benzer ölçekler kullanılmaktadır (örn., "Partnerim ne düşündüğümün ve hissettiğimin farkındadır", "Partnerim yeteneklerime ve fikirlerime değer verir", "Partnerim benden hoşlandığını gösterir ve beni cesaretlendirir"; Reis, 2007, sf. 13). Bu çalışmanın devamında bahsi geçen çalışmaların çoğunda değerlendirme yöntemi olarak ikinci yöntem kullanılmıştır. Günümüzde ilk kez Reis ve Carmichael'in (2006) yayınlanmamış çalışmasında yer alan 18 maddelik ölçek (örn., "Partnerim gerçek beni görür"), bu ölçeğin 12 maddelik sürümü ve özellikle günlük çalışmalarında APD'nin üç ana unsurunun aktöre doğrudan sorulduğu maddeler (örn., "Partnerim beni anlar.", Maisel ve Gable, 2009) kullanılmaktadır (Reis, Crasta, Rogge, Maniaci ve Carmichael, 2018). Gözlem ve özdeğerlendirme sürecini birlikte kullanan çalışmalarda ise aktör ve gözlemci raporları karş1laştırılarak herhangi bir algısal farklılık olup olmadığ saptanmaya çalışılmıştır. Bir sonraki kısımda APD’nin kişisel ve ilişkisel bağlamdaki rolünü destekleyen yakın ilişki kuramları ve APD çalışmalarına ayrıntılı olarak değinilmiştir.

\section{APD'nin Kişisel ve İlişkisel Sonuçları}

Reis'e göre (2007), APD yakın ilişkilerin kilit unsurudur ve kişisel (örn., güvenli bağlanma), partnere özgü (örn., affetme), etkileşimsel (örn., empatik anlayış), benlik düzenleyici (örn., öz-doğrulama) ve üst bilişsel yapılar (örn., aidiyet hissi) gibi ilişkilerle bağlantılı birçok yapı belirli derecelerde APD'yi içerir. Bu görüş birçok kuramsal yaklaşımda da desteklenmektedir.
Örneğin, bağlanma kuramı bağlanma figürü tarafından ihtiyaçlarına duyarlık gösterilen kişilerin kendilerine ve diğer kişilere yönelik daha tutarlı ve olumlu zihinsel temsillere sahip olduğunu öne sürer. Eğer bağlanma figürünün varlığ 1 ve duyarlığ1 kişinin ihtiyaçlarını karşlamada yetersiz kalırsa güvensizlik hissi artar ve kişinin kendine ve diğer insanlara yönelik olumsuz zihinsel temsilleri etkin hale gelir (Mikulincer ve Shaver, 2003). Diğer bir deyişle, güvensiz bağlanma temelli bir ilişkide kişi partner duyarlığına yönelik olumsuz bir algı geliştirebilir ve bu da kişisel ve sosyal ilişkilerdeki duygu düzenleme süreçlerine olumsuz yansıyabilir. Karşılıklı bağımlılık (interdependence) kuramına göre ise yakınlık ilişkilerin ana unsurudur. Kişi partneri tarafından yakınlık ihtiyacının karşılanmasını bekler. Kendini açtığı durumlarda da partnerinden destek göreceğine dair güvene ihtiyaç duyar (Holmes, 2002). Bu sebeple, APD güçlü bağımlı ilişkiler kurmada önemli bir yere sahiptir. Öz-belirleme (self-determination) kuramı ise yakın kişilerin birbirlerinin temel psikolojik ihtiyaçlarını karşılamada önemli bir rol oynadığını söyler. Duyarlı partner koşulsuz destek ve sayg1 göstererek üç temel ihtiyaç olan kişinin yeterlik, özerklik ve ilişkili olma güdülerinin gelişmesine katkı sağlar. İhtiyaçların karşılanmasından doğan doyum da psikolojik esenlik ve ilişkide mutluluk ile sonuçlanır (Deci ve Ryan, 2000; La Guardia ve Patrick, 2008). Dolayısıyla bir dış etken olarak APD'nin içsel motivasyonlarla yakından ilişkili olduğu söylenebilir (Ibarra-Rovillard ve Kuiper, 2011). Ayrıca APD, partnerin duyarlı olduğunu hissetmenin partnere duyulan güveni artırdığını belirten kişilerarası güven modeli ile de yakından ilişkilidir (Murray, Holmes ve Collins, 2006; Reis, 2007). Söz konusu kuramlar APD'nin kişisel ve sosyal işlevlerin sürdürülmesinde dikkate değer bir yap1 olduğunu işaret etmektedir. APD'nin psikolojik esenlik, benlik düzenleme ve ilişkisel çıktılar üzerindeki önemini vurgulayan çalışmaların bulguları aşağıda sunulmuştur.

\section{APD ve Psikolojik Esenlik}

Anlayan, değer veren ve ilgi gösteren partner kişinin iyi hissetmesinde ve yaşam kalitesinin artmasında önemli bir yere sahiptir. APD'nin psikolojik ve fiziksel esenliğe katkısı son dönemde yapılan boylamsal çalışmalarla gösterilmiştir. Yüksek düzeydeki APD’nin kişinin 10 yıl sonraki anlamsal (eudaimonic; kendini gerçekleştirme ve yaşamda anlam bulma) esenliğini olumlu yönde yordadığı bulunmuştur (Selçuk, Günaydın, Ong ve Almeida, 2015). Diğer bir çalışmada, başlangıçta yüksek APD rapor eden kişilerin, 10 yil sonraki günlük kortizol eğimlerinin, daha düşük APD rapor eden kişilere göre daha dengeli olduğu bulunmuştur. Kişiler araştırma sürecinde var olan ilişkilerini sonlandırıp başka bir ilişkiye başlamış olsalar dahi başlangıçta rapor ettikleri APD 
ile kortizol seviyesi arasındaki bağlant1 10 y1l sonunda aynı düzeyde varlığını sürdürmüştür (Slatcher, Selçuk ve Ong, 2015). Başka bir çalışmada, APD'nin düşük kayg1 ve depresyon aracılığıyla öznel uyku problemleri üzerinde olumlu bir etkisi olduğu ve APD'nin düşük kayg1 aracılığıyla nesnel uyku kalitesi izlemini olumlu yönde yordadığı bulunmuştur (Selçuk, Stanton, Slatcher ve Ong, 2017). Yeni evli çiftlerin katıldığı bir çalışmada ise eşlerini duyarlı algılayan kadınların ve erkeklerin 9 yıllık sürede aşamalı olarak sigarayı bıraktığı, duyarlı algılamayanların sigara birakma konusunda herhangi bir gelişim kaydetmediği görülmüştür (Derrick, Leonard ve Homish, 2013). APD yaşam süresine de olumlu katkıda bulunmaktadır. Bir çalışmada, duygusal desteğin ölüm riskiyle olan ilişkisinde APD'nin düzenleyici etkisi olduğ ve duygusal destek aldığını rapor edenlerin aynı zamanda düşük APD rapor etmeleri durumunda hala ölüm risklerinin yüksek olduğu gösterilmiştir (Selçuk ve Ong, 2013). Bu sonuca göre partneri duyarlı algılamanın hayatta kalmak için önemli bir destekleyici unsur olduğunu söylemek mümkündür.

Bazı araştırmacılara göre, APD'nin psikolojik esenlik üzerindeki etkisinin temelinde hem nesnel hem yanlı algısal süreçler yer almaktadır (Lemay, 2014). Bu görüşü destekleyen çalışmalarda partnerin gerçek duyarlık davranışı aktörün APD seviyesini yükseltmiş, bu da aktörün kişisel bir problemini çözmeye dair özyeterliğinin artması ile sonuçlanmıştır (nesnel algı). Bu etkiden bağımsız olarak, partnere verilen değer arttıkça aktörün APD düzeyi artmış, bu da aktörün psikolojik esenliğini olumlu yönde yordamıştır. Aktörün partnerine çok fazla değer vermediği durumda ise aktörün APD düzeyinin partnerin gerçek duyarlık davranışından daha düşük olduğu (yanlı alg1) görülmüştür (Lemay ve Neal, 2014). Diğer bir deyişle, aktör partnerine değer verdiğinde ve partner duyarlık gösterdiğinde aktörün partnerini duyarlı algılama eğilimi artmakta, bu artış da aktörün psikolojik esenliğine olumlu yönde yansımaktadır.

Özetle, partner duyarlığı kişilerin daha iyi hissetmesi, sağlıklı davranışlar geliştirmesi ve daha kaliteli bir yaşam sürmesine katkıda bulunmaktadır. Aynı zamanda, APD'nin bireysel sonuç değişkenleri üzerindeki rolü kişilerin algılarını doğrudan veya yanlı olarak belirleyen bazı unsurlara göre değişebilmektedir. Sonraki kısımda APD'nin benlik düzenleme süreçlerindeki rolü ile ilgili çalışmalara yer verilmiştir.

\section{APD ve Benlik Düzenleme Süreçleri}

Partner duyarlığı kişinin başarısızlığa yönelik tutumunu düzenlemesi ve kişisel hedeflerine ulaşması için gerekli olan benlik düzenleme süreçlerini etkiler ve şekillendirir. Örneğin, deneysel bir çalışmada APD ile bir hedefe yönelik bilişsel süreçlerin ilişkisi incelenmiştir.
Verilen görevi yerine getirme konusunda başarısız olduğu geri bildirimi verilen katılımcilardan partnerinin duyarlığı hakkında düşünmesi istenenler, bir yakınını veya arkadaşını düşünmesi istenenlere göre, başarısızlıkla ilgili tehdit karşısında daha az savunmacı tutum sergilemiştir (Caprariello ve Reis, 2011). Bu çalışma başarısızlığa yönelik savunmacı tutumların azalmasında APD'nin işlevselliğini vurgulaması açısından önemlidir. Düzenleyici odak (regulatory focus) kuramı çerçevesinde yürütülen bir çalışmada, hedeflerini partnerleriyle paylaşan kişilerin farklı odak tiplerine (gelişme odaklı ve koruma odaklı) sahip olmalarına bağlı olarak APD düzeylerinin nasıl değiştiği incelenmiştir. Kronik gelişme odaklı kişiler partnerleriyle desteğe ilişkin hedeflerini paylaştıklarında, korumaya ilişkin hedeflerini paylaştıkları zamana göre daha açık bir şekilde kendilerini açma ve partnerlerini duyarlı algılama eğiliminde olmuşlardır. Kronik koruma odaklı kişiler ise konuşma esnasında daha mesafeli olarak kodlanan partnerlerini daha duyarlı olarak algılamışlardır. Kişiler partnerlerini daha duyarlı algıladıklarında ise korumaya ilişkin hedeflerini daha az zarar verici olarak değerlendirmişlerdir (Winterheld ve Simpson, 2016).

APD'nin bireysel hedefler üzerindeki etkisini gösteren evli çiftlerle yürütülen boylamsal bir çalışmada sosyal desteğin üç temel unsurunun (algılanan destek, algılanan duyarlık ve verilen/asıl destek) benlik kavra$\mathrm{m}$ üzerindeki etkisi incelenmiştir. Aktörler bireysel hedeflerini paylaştıkları sırada partnerlerin verdiği gerçek destek (örn., duygusal ve araçsal destek, hedefe ulaşabilmesi için rahatlatma ve hassas bakım) davranışları kodlanmıştır. Davranışları olumlu olarak kodlanan partnerler aktörler tarafından da duyarlı olarak algılanmış ve bu da aktörlerin paylaşımdan hemen sonra ölçülen hedeflerini gerçekleştirmeye yönelik algılarını olumlu yönde etkilemiştir. Hedefi gerçekleştirme algısı yükseldikçe de ilk çalışmayı takip eden dönemde aktörün kendini geliştirme ve özsaygı düzeylerinin yanı sıra hedefe ulaşma olasılığında da artış olduğu bulunmuştur (Tomlinson, Feeney ve Van Vleet, 2016).

Özet olarak, partnerinin benlik gelişimi konularında kendisine anlayışlı ve ilgili davrandığını ve değer verdiğini hisseden aktörler kişisel başarısızlıklarını telafi etme ve hedefleri gerçekleştirme yolundaki süreçleri olumlu değerlendirme eğilimindedir. APD kişisel başarı ve kazanımları pekiştirmesinin yanı sıra partnere duyulan yakınlık hissi, ilişkiden alınan doyum ve mutluluğu artırmaktadır. Sonraki kısımda APD'nin ilişkisel süreçlerdeki rolüne yönelik çalışmalara yer verilmiştir.

\section{APD ve İlişkisel İşleyiş}

Yapılan birçok çalışmada APD’nin ilişkilere özgü süreçlerdeki rolüne değinilmiştir. Bunlar arasında yakın- 
lık, doyum, romantik ilgi, affetme, ilişkisel tehdit, duygu düzenleme ve cinsel ilgi yer almaktadır. Çalışmaların bir kısmı kendini açma ve APD ilişkisini temel alırken bir kısmı bu ilişki dışında APD'nin görülebileceği etkileşimsel durumlara değinmiştir. Bazı çalışmalar da aktörün kişilik özellikleri ile aktör ve partnere ilişkin bazı dinamiklerin APD üzerindeki olası etkilerini incelemiştir.

APD’nin ilişkisel bağlamdaki rolünü araştıran ilk çalışmalar, kendini açma sırasında ortaya çıkan yakınlık sürecinin incelenmesiyle başlamıştır. Reis ve Shaver'in (1988) yakınlık modelini günlük sosyal etkileşim deseninde çalışan araştırmacılar çiftlere her bir etkileşimlerinde partnerleriyle ne kadar olay, düşünce ve duygu paylaşımında bulunduklarını sormuştur. Bulgular hem aktörün hem partnerin kendini açma davranışlarının APD'yi yordadığını, bunun da yakınlık hissini artırd1ğını göstermiştir (Laurenceau, Barrett ve Pietromonaco, 1998). Düşük APD’nin etkisini gösteren başka bir günlük çalışması ise kişinin gün içinde yaşadığı endişe, problem veya zorluklar karşısında beklediği destek partneri tarafından gösterilmediğinde partnerini duyarsız algıladığını, bunun da ilişkiye yönelik günlük olumlu duyguların azalmasına neden olduğunu göstermiştir (Bar-Kalifa ve Rafaeli, 2013). Bir hızlı tanışma (speed dating) çalışmasında, APD'nin ve aktörün duygusal deneyimlerinin yeni bir partnere yönelik romantik ilgiyi nasıl etkilediği incelenmiştir. Aktörün partneri duyarlı algıladığında kendisini daha olumlu duygularla (örn., coşkulu, mutlu, rahat) tanımladığı, bunun da o partnere yönelik romantik çekimi artırdığı bulunmuştur (Berrios, Totterdell ve Niven, 2015). Bu çalışmalarla kişinin kendiyle ilgili paylaşımlarda bulunduğunda partner duyarlığını hissetmesinin yakınlık hissi, ilişki memnuniyeti ve partneri çekici algılamak adına önemli bir gereklilik olduğu vurgulanmıştır.

Bazı araştırmacılara göre kendini açma dişında başka bağlamlarda da yakın hissetmek, cinsel istek hissetmek ve ilişkide mutlu olmak için partner duyarlığ 1 gerekli görülmektedir. Örneğin, Debrot, Cook, Perrez ve Horn (2012) yaptıkları günlük çalışmasında, partnerin duyarlık davranışı (örn., nazik bir mektup bırakma, sarılma) ve bu davranış sonrasında hissedilen yakınlık arasında APD'nin aracı rolünü göstermişlerdir. Bu çalışmada, ayrıca, APD'nin aktörün kendi duyarlık davranışıyla ilişkili olduğu ve bunun kendi yakınlık hislerini de artırdığı bulunmuştur. Bu ileride değinilecek olan duyarlığın "yansıma" etkisine iyi bir örnektir (Lemay, Clark ve Feeney, 2007). Diğer bir günlük çalışmasında ise aktörün partneri duyarlı algıladığı günlerde kendini daha özel hissettiği, partnerini daha değerli gördüğü ve sonuçta bunların hem erkeklerde hem de kadınlarda partnere karşı cinsel isteği artırdığı bulunmuştur (Birnbaum ve ark., 2016). Başka bir çalışmanın sonuçlarına göre, partnerine yönelik minnet duygularını paylaştıktan sonra APD'yi değerlendiren aktörler kendini açtıktan sonra APD'yi değerlendirenlere göre daha yüksek ilişki doyumu, günlük uyum, olumlu duygu ve yaşam doyumu rapor etmiştir (Algoe ve Zhaoyang, 2016). Rusbult'1n yatırım modelindeki üç ana unsurun (ilişki doyumu, ilişkiye yapılan yatırımlar ve seçeneklerin niteliğinin değerlendirilmesi) önemli belirleyicilerinden birinin APD olabileceğini öne süren bir çalışmada ise, APD ve ilişkisel bağlılık arasında bu üç unsurun aracı değişken rolü test edilmiştir. Hem kişi içi hem kişiler arası desenlerde yüksek APD, doyum ve yatırımı olumlu yönde, seçeneklerin niteliğinin değerlendirilmesini ise olumsuz yönde yordamış, bu üç unsur da ilişkisel bağlılıkla ilişkili bulunmuştur (Segal ve Fraley, 2016).

APD'nin çatışma durumlarındaki rolünü inceleyen çalışmalar da bulunmaktadır. Gordon ve Chen (2016) çalışmalarında APD'nin üç temel unsurundan biri olan anlaşılma algısını ele almıştır. Partneriyle yaşadığı bir tartışması hatırlatılan aktör tartışma sırasında partnerinin anlayışlı olduğunu düşündüğünde ilişkisinde daha fazla mutlu olduğunu belirtmiştir. Diğer bir çalışmada, katılımcılardan stres yaratan ve partnerin özür davranışıyla sonuçlanan bir tartışmayı hatırlamaları istenmiştir. Aktör partnerin özür davranışının (örn., özür dileme, sorumluluğu üstlenme, telafi etme, pişman olma) içtenliğine inandığı durumda, partnerin kendisine değer verdiğini ve üzüntüsünü anladığını düşünmüş ve onu affetme olasılığı yükselmiştir (Pansera ve La Guardia, 2012). Bu bulgular APD'nin tartışmanın olumsuz etkilerine karşı bir tampon olabileceğini göstermesi açısından önemlidir.

Partner duyarlığının ilişkisel çıktılardaki etkileri kişilerarası gerçek bir etkileşim olmadan, örtük ölçümlerle de gözlenmiştir. Deneysel bir çalışmada dijital gözlük kullanılarak katılımcılar için yeni ve tehdit edici unsurlar içeren bir görev (uçurum kenarında yürümek) hazırlanmıştır. Katılımcılar bu görev esnasında görsel olarak hazırlanan üç ayrı koşuldan birine dâhil edilmiştir. Bir kısmı bu görevi yalnız gerçekleştirirken bir kısmı duyarlı partnerleriyle, diğerleri de duyarsız partnerleriyle tamamlamıştır. Duyarlı partneriyle görevi tamamlayanlar diğer gruplardakilere göre görevi daha az stresli olarak değerlendirmiş, daha yüksek duygusal güven ve APD rapor etmiştir. Duyarlı bir partnere sahip olmanın rahatlama ve güven duygularını pekiştirdiği, duyarsız partnerin ise rahatsızlık ve kaçınma duygularını tetiklediği sonucuna varılmıştır (Kane, McCall, Collins ve Blascovich, 2012). Buna benzer çalışmalar olağan dış1 durumlarda dahi duyarlı partnerin yatıştırıcı etkisinin görülmesi açısından önemlidir.

Özetle, ilgili yazında yakınlık, ilişki doyumu, uyum, cinsellik, güven, affetme, çatışma gibi farklı ilişkisel bağlamlarda partner duyarlığının ve etkileri- 
nin gösterildiği birçok çalışma bulunmaktadır. APD'yi etkileyen bireysel farklılıkların da bu ilişkisel süreçler üzerinde dolaylı bir etkiye sahip olması mümkündür. Bir sonraki kısımda APD'yi etkileyen bireysel farklılıklar ele alınmıştır.

\section{Bireysel Farklılıkların APD Üzerindeki Etkisi}

APD'nin ilişkisel çıktılar üzerindeki rolünü inceleyen bazı araştırmacılar, APD üzerinde özsayg1, sosyal kaygı, ilişkisel hak iddia etme hissi, farkındalık düzeyi, bağlanma yönelimi ve cinsiyet gibi kişisel özelliklerin ya da bireysel farklılıkların olası etkilerini incelemiştir. Kendini açma ve APD ilişkisini deneysel ortamda ilk kez inceleyen bir çalışmada aktörlerden sözde partnerlere vermek üzere kişisel mutsuzluk yaratan bir olayı yazmaları istenmiştir. Düşük özsaygıya sahip aktörlerin partnerden duyarlı bir yanıt aldıklarında kendilerini ifade etme konusunda yüksek özsaygıya sahip olanlara göre daha istekli olduğu bulunmuştur (Forest ve Wood, 2011). Benzer bir çalışmada, düşük özsaygıya sahip bireylerin partnerlerini daha az duyarlı algılamasının yalnızca kendi zihinsel süreçlerinden kaynaklanmadığ 1 , bu kişilerin partnerlerinin de daha düşük duyarlık gösterme eğiliminde olduğu bulunmuştur. Bunun sebebinin de düşük özsaygılı bireylerin olumsuz kişisel deneyimlerini partnerlerine anlatırken yeterince dürüst olmaması ve dolay11 olarak aktarması olabileceği öne sürülmüştür (Cortes ve Wood, 2018). Diğer bir çalışmada, yüksek sosyal kaygının APD'yi olumsuz yönde yordadığı, bunun da hem günlük hem de belirli bir zaman sonraki doyumu düşürdüğü bulunmuştur (Bar-Kalifa, Hen-Weissberg ve Rafaeli, 2015). Sosyal kaygısı yüksek bireylerin sosyal uyaranlara karşı olumsuz atıflarda bulunması, bu kişilerin partner duyarlığını değerlendirirken yanlılığa yatkın olmaları ile açıklanabilir (bkz., Lemay ve Neal, 2014). Bir günlük çalışmasında narsisizmin ilişkisel bir parçası olarak görülen ilişkide hak iddia etme hissiyatının (sense of relational entitlement) APD ile ilişkisi incelenmiştir. $\mathrm{Bu}$ narsistik eğilim kendi dilek, ihtiyaç ve hayallerinin gerçekleşmesinde aşırı derecede partnerinden destek beklemek olarak tanımlanmıştır. Bu eğilimi yüksek olan kişiler destek ihtiyaçlarının karşılandığını düşündükleri günlerde daha yüksek düzeyde APD rapor etmiştir (Bar-Kalifa, Bar-Kalifa, Rafaeli, George-Levi ve Vilchinsky, 2016). Çiftlerle yapılan güncel bir çalışmada ise farkındalığın (mindfulness) alt kategorilerinin (eleştirel olmama, gözlemleme, bilinçli hareket etme, tepkisel olmama, tanımlama) APD ile olan ilişsisinin yakın ilișkiye nasıl yansıdığ1 araştırılmıştır. Eleştirel olma düzeyleri düşük, gözlem düzeyleri yüksek olan kişiler partnerlerini daha duyarlı algılamış, bu da ilişski doyumunu olumlu yönde yordamıştır. Bilinçli hareket etme düzeyi yüksek kişilerin hem kendi APD düzeyleri hem de partnerleri- nin onlar hakkındaki duyarlık değerlendirmeleri yüksek bulunmuş, bunlar da yüksek ilişki doyumu ile sonuçlanmıştır. Bulgulara göre, partneri duyarlı algılayabilmesi adına kişinin farkındalık düzeyinin yüksek olması önkoşullardan biri olarak değerlendirilebilir (Adair, Boulton ve Algoe, 2018).

Çalışmalar partner duyarlığındaki algısal farklılıkları açıklamak amacıyla bağlanma dinamiklerini de göz önünde bulundurmuştur. Bir çalışmada çiftler arasındaki mutluluk paylaşımı (capitalization) ve tartışma esnasında bağlanma ve APD ilişskisi laboratuvar ortamında incelenmiştir. Bağlanmaya ilişkin kaçınma düzeyleri yüksek partnerler daha az duyarlı olarak değerlendirilmiştir. Bağlanmaya ilişkin kaygı düzeyleri yüksek aktörler partner duyarlığını gözlemlenenden daha düşük değerlendirme eğilimi göstermiştir. Kaygılı bağlanan bireyler yakın ve güvenli ilişkiler kurmak istediklerinden paylaşımların karşılıklı olarak olumlu sonuçlanmasını umarken; kaçınan bağlanan partnerler kendilerini açma ve mutluluk paylaşımına olumlu karşılık verme konusunda aktörleri tatmin etmekte zorlanmıştır (Shallcross, Howland, Bemis, Simpson ve Frazier, 2011). Başka bir çalışmada yalnızca kaçınan bağlanma ile düşük APD ilişkilendirilmiştir. Kaçınan bağlanan kişiler laboratuvarda partnerleriyle bir konu üzerinde tartıştıktan sonra kendilerini daha az duyarlı olarak değerlendirmiştir. Bu kişilerin partnerleri de düşük APD rapor etmiştir. Kaçınan bağlanmanın bir sonucu olarak bu bireyler yakınlık ihtiyacını bastırma, buna bağlı olarak da duyarlık davranışını bağımsızlıklarına yönelik bir tehdit olarak algılama eğiliminde olabilmektedir. Bu da partnerlerinin paylaşımlarını azımsamalarına ve duyarlı davranışlardan uzak durmalarına yol açabilmektedir (Beck, Pietromonaco, DeVito, Powers ve Boyle, 2014). Bu bulgulara bakıldığında, kaçınan bağlanan bireylerin partnerlerinin duyarlı olmasını hiçbir şekilde beklemedikleri akla gelmektedir. Bu çıkarımı test etmek amacıyla, kaçınan bağlanan bireylerin yakınlık isteğine göre duyarlık algılarının ve isteklerinin değişip değişmediği deneysel bir çalışma ile incelenmiştir. Kendilerine verilen bir notta, karşı cinsin duyarlı veya duyarsız olduğunu okuyan kaçınan bağlanan kişiler, yüksek düzeyde duyarlı kişilere karşı yakınlık kurma ihtimalini, romantik ilgiyi ve benzerlik algısını düşük olarak beyan etmişlerdir. Bu bağlantı kaygılı bağlanan kişilerde ve düşük duyarlık düzeyine sahip kişilere yönelik değerlendirmelerde anlamlı bulunmamıştır. Bu da kaçınan bağlanan bireylerin tüm ilişkileri bağımsızlıkları için bir tehdit olarak görmüyor olabileceğini, yalnızca fazla duyarlık gösteren kişilerle, duygusal yakınlığı artırma ihtimaline karşı mesafelerini korumayı tercih ettiklerini göstermiştir (Spielman, Maxwell, Macdonald ve Baratta, 2013). $\mathrm{Bu}$ bulgular kaygılı bağlanan bireylerin APD'yi en aza indirme, kaçınan bağlanan bireylerin ise duyarlı olmak- 
tan ve duyarlı partnerlerle birlikte olmaktan uzak durma eğiliminde olduğunu göstermektedir. Bu durumda düşük düzeydeki APD'nin en olumsuz etkisinin kaygıl1-kaç1nan bağlanan çiftlerde yaşanabileceğini söylemek mümkündür.

APD yazınında kadın ve erkeklerin duyarlığı aynı bakış açısıyla değerlendirip değerlendirmedikleri de ele alınmıştır. Evli çiftlerle bu farkı sınamak için düzenlenen günlük çalışmasının bulgularına göre APD ve yakınlık ilişkisi kadınlarda erkeklere göre daha yüksektir. Partnerin kendini açması ve yakınlık ilişkisinde APD'nin aracı rolünün kadınlar için daha güçlü olduğu bulunmuştur (Laurenceau, Barrett ve Rovine, 2005). Bu da kadınların ilişkilerinde yakınlık hissetmek için APD'ye daha fazla önem verdiklerini göstermektedir. $\mathrm{Bu}$ durum yakınlık yerine cinsel çekicilik söz konusu olduğunda değişmektedir. Bağlanma boyutları ve cinsiyetten kaynaklı algısal farklılıkları araştıran Birnbaum ve Reis (2012), düşük kaçınan bağlanan kişilerde, yüksek kaygılı bağlanan kişilerde ve erkeklerde APD ve cinsel arzu ilişkisinin daha yüksek olduğunu bulmuştur. Yeni tanışan partnerlerle yapılan bir deneysel çalışmada erkeklerin APD değerlendirmesinin partner "kadınsılığını" belirlediği, bunun da cinsel arzuyu artırdığı gösterilmiştir. Erkeklerde APD ile cinsel uyarılma arasında doğrudan bir ilişki olduğu, bunun da algılanan çekiciliği ve partnerle uzun süreli ilişki yaşama isteğini olumlu yönde yordadığ miştir (Birnbaum, Ein-Dor, Reis ve Segal, 2014). Bu bulgular özellikle erkekler için cinsel ilgiyi belirlemede APD'nin temel bir unsur olduğunu göstermektedir. Kadınlar ise cinsel ilgiden ziyade yakınlık hissi için yüksek partner duyarlığına ihtiyaç duymaktadır.

\section{APD'yi Yordayan Aktöre Bağlı ve Partnere Bağlı Dinamikler}

Bazı araştırmacılar kişisel özelliklerin dışında aktöre bağlı başka dinamiklerin de APD'nin ilişkisel çıktılarla olan bağlantısını açıklayabileceğini savunmuştur. Lemay, Clark ve Feeney (2007) duyarlığın yansıması adını verdikleri bir model önermiştir. Bu modele göre, APD'nin belirlenmesinde aktörün kendi duyarlığ 1 partnerin asıl duyarlığından daha güçlü bir yordayıcıdır. Aktör partneri açık yüreklilikle desteklediğinde aktörün hissettiği duyarlık daha tatmin edici olmaktadır. Bu öngörüyü test etmek amacıyla evli çiftlerle bir çalışma yürütülmüştür. Duyarlık, bağlanmanın iki temel unsuru olan güvenli üs ve güvenli sığınak çerçevesinde değerlendirilmiştir. Aktörün kendi duyarlığı APD'yi hem güvenli üs hem güvenli sığınak bağlamlarında partnerin beyan ettiği duyarlıktan daha yüksek düzeyde yordamıştır. Aktör duyarlı ise bu duyarlık hem partnerine hem de kendi algıladığ partner duyarlığına olumlu yansımaktadır. Ayrıca, bağlanma boyutları ve özsaygı kontrol edildiğinde APD'nin kişinin kendi duyarlığı ve evlilik doyumu arasında aracı değişken rolüne sahip olduğu gösterilmiştir. Uzun vadeli etkiyi göstermek adına yapılan günlük çalışmasındaysa partnerine kronik duyarlık gösteren kişilerin partnerin rapor ettiği yararların sayısından bağımsız olarak partner duyarlığını oldukça yararlı bulduğu sonucuna varılmıştır. Bu çalışma ile aktörün kendi duyarlık davranışlarının olas1 etkilerinin göz önünde bulundurulması ve bu konudaki çalışmaların çift taraflı bakış açısıyla yürütülmesi gerekliliği vurgulanmıştır. Bir diğer aktöre bağlı değişken ise Lemay ve Neal (2013) tarafından önerilmiştir. Buna göre, eğer kişi ilişkisini önemsiyorsa partnerinin davranışlarını duyarlı olarak, ilişkisine yeteri kadar değer vermiyorsa partner davranışlarını duyarsız olarak hatırlama ve kaydetme eğiliminde olabileceği varsayılmıştır. Bu yanlılığa "duyarlığın hayali hafızası" (wishful memory of responsiveness) adı verilmiştir. Günlük çalışmaları ve boylamsal çalışmalar yürüten araştırmacılar, aktörün partnere verdiği değerin (bağlılık, özen ve sayg1) partnerin duyarlığına dair anıları olumlu yönde etkilediğini bulmuştur. Partnerine daha az değer veren aktörlerin olumsuz hafıza yanılgıları olduğu gösterilmiştir. Ayrıca, yeni evli çiftlerle yapılan bir çalışmada, kişinin cinsel doyumunun yüksek olduğu günlerde partnerini daha duyarlı algıladığı bunun da evlilik doyumunu artırdığ 1 görülmüştür (Gadassi ve ark., 2016). Tüm bu bulgular APD değerlendirmesinde aktörlerin yalnızca birer gözlemci değil, aynı zamanda kendi algılarını etkileyebilen aktif kişiler olduğunu göstermektedir.

Aktöre bağlı dinamiklere ek olarak partnere bağl1 dinamikler de partner duyarlığını yorumlamada etkilidir. Bunlardan biri olan partnerin gerçek duyarlı davranışlarının APD üzerindeki rolüne yukarıda yer verilmiştir. Bir diğeri ise partnerin empati düzeyidir. Bir çalışmada empatik doğruluk (partnerinin duygu ve düşüncelerini tutarlı olarak doğru anlama) ve empatik ilgi (partnere yönelik olumlu davranışta bulunma güdüsü) biçimlerinin APD'nin yordayıcıları olabileceği ileri sürülmüştür. Laboratuvar ortamında çiftler arasında stres yaratan bir konu hakkında etkileşimde bulunmaları istenmiş ve APD hem aktörler hem gözlemciler tarafindan değerlendirilmiştir. Bulgulara göre, partnerin empatik ilgi düzeyi yüksek olduğunda (örn., kendini partnerine karş1 şefkatli hissettiğinde) partnerin empatik doğruluk düzeyi APD'yi olumlu yönde yordamıştır. Empatik ilgi düzeyi düşük olduğunda ise empatik doğruluk yüksek APD düzeyi için yeterli olamamıştır (Winczewski, Bowen ve Collins, 2016). Buradan çıkarımla, partnerin aktörün duygu ve düşüncelerine yönelik samimiyetinin kendi duyarlı davranışlarının aktöre doğru biçimde aktarılıp aktarılmadığını belirlediğini söylemek mümkündür. 


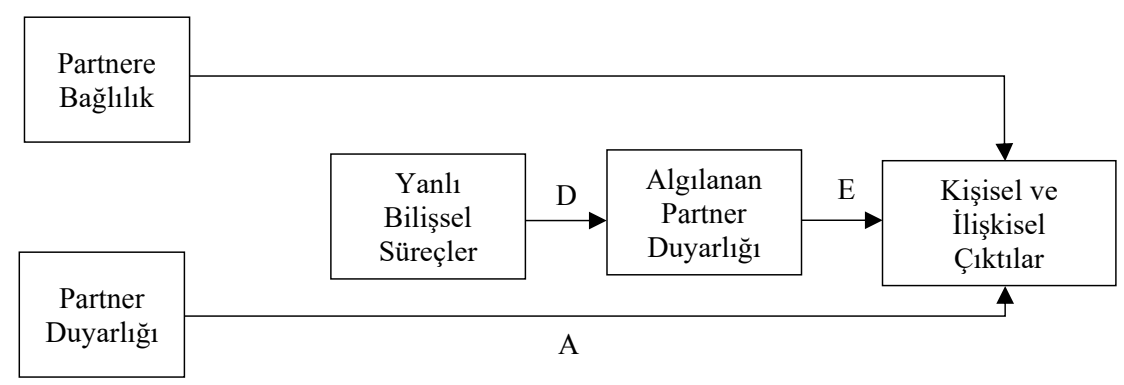

Şekil 2. Partner Duyarlığına Yönelik Motive Algılar Modeli (Lemay ve Clark, 2015).

\section{Duyarsız Partner İlişsisiyle Başa Çıkma}

Şimdiye kadar bahsedilen çalışmalarda duyarlı algılanan partnerin kişiye ve ilişkiye olan katkısından ve partneri duyarlı algilayabilmede rol oynayan unsurlardan söz edilmiştir. Bunların yanı sıra duyarsız bir partneri olan kişilerin bununla nasıl başa çıktığı da araştırılmıştır. Lemay ve Melville'e (2014) göre, geçmiş çalışmalar kendini açmanın ters etkisini göz ardı etmiştir. Kişiler partnerlerinin umursamaz, düşmanca veya benmerkezci olduğunu düşündüğünde onlarla kişisel yaşantılarını paylaşmaktan kaçınabilirler. Çünkü paylaşıma karşılık alınamadığında reddedilme riski artabilir, bu da partnere olan güveni ve bağl1lığı sarsabilir. Bu nedenle, kendini ifade etmenin duyarsılıkla sonuçlanabileceğini öngörmek partner duyarsızlığının etkilerinin önlenmesini ve kişilerarası bağlılığın sürdürülmesini sağlayabilir. $\mathrm{Bu}$ süreç bireylerin APD'ye giden yolda aktif rol üstlendiklerini ve paylaşımların APD üzerindeki olası sonuçlarını önceden değerlendirmeye aldıklarını bir kez daha vurgulamaktadır. Araştırmacıların çiftlerle yürüttükleri bir dizi çalışmanın sonuçlarına göre, ilişkilerine bağlı kişiler partnerlerinin daha az duyarlık göstereceğini sezdikleri günlerde daha az paylaşımda bulunmuştur. Beklenen partner duyarlığ partnerle paylaşılan durumların olumlu veya olumsuz olmasına göre de değişebilmektedir. $\mathrm{Bu}$ konuda yapılan çalışmada, APD doğrudan ölçülmemiş ancak aktörlerin duyarlık algısını etkilemek amacıyla partner davranışları aktif (istekli bir şekilde anlayış gösterme ve değer verme) ve pasif (yardım etmekten ve ilgi göstermekten kaçınma) olarak manipüle edilmiştir. Aktörlerin kendilerini geliştirmeye yönelik veya stres yaratıcı iki görevden birine katılmaları sağlanmıştır. İlk göreve katılan aktörler partnerlerinden aktif unsurlar içeren yazılı bir mesaj aldıklarında, pasif içerikli mesaj alanlara göre daha fazla ilişki doyumu beyan etmiştir. İkinci göreve katılan aktörlerin ilişki doyumu ise partnerlerinden pasif unsurlar içeren mesaj aldıklarında aktif içerikli mesaj alanlara göre daha yüksek olmuştur. Bu bulgulara göre, stres anında aktif bir destek görmeden partnerin yalnızca güvenini hissetmek dahi stresle başa çıkmak için yeterli olabilmektedir. Yine de aktif destek aktörlerin kendilerini geliştirmelerine yönelik etkinliklerde bulunabilmeleri açısından kritik bir öneme sahiptir (Fivecoat, Tomlinson, Aron ve Caprariello, 2015). Mutluluk paylaşımı çalışmaları da bu öneriyi destekler niteliktedir. Olumlu kişisel olayları paylaşan aktörlerin partnerleri ancak ve ancak aktif-yapıcı karşılık verdiğinde ilişsisel tatmin yaşadığı görülmüştür (Gable, Reis, Impett ve Asher, 2004). Sonuç olarak, kişinin partneriyle kişisel paylaşımlarda bulunabilmesi, partnerin uygun bir karşılık vereceğini öngörmesine ve ilişkisel mutluluğu yaşayabilmesi de partnerin, vereceği tepkiyi paylaşımın içeriğine bağlı olarak düzenlemesine bağlıdır.

Şimdiye kadar sunulan çalışmalar çiftler arası çeşitli etkileşim bağlamlarında APD'nin kişisel ve ilişkisel çıktılar üzerindeki olumlu, kalıcı ve uzun süreli etkilerini ve aktöre ve partnere bağlı belli unsurların APD sürecindeki rolünü göstermiştir. Aktörün yalnızca algılayan değil aynı zamanda algıyı yöneten kişi de olabildiği vurgulanmıştır. Bir sonraki kısımda aktöre ve partnere özgü motivasyonları açıklamaya odaklanan güncel APD modellerinden bahsedilmiştir.

\section{Önerilen APD Modelleri}

Geçmiş çalışmaların 1şı̆̆ında geliştirilen iki APD modeli bulunmaktadır. APD'ye yönelik doğruluk ve yanlılık motivasyonlarını inceleyen çalışmaları (Lemay, Clark ve Feeney, 2007; Lemay ve Neal, 2013; 2014) temelinde, Lemay ve Clark'ın (2015) önerdiği modelde (bkz., Şekil 2) partnerin gerçek duyarlığının APD üzerindeki doğrudan etkisinin doğruluk motivasyonunu açıkladığ1 (A) belirtilmektedir. Bundan bağımsız olarak aktörün partnere dair duygularının hem doğrudan (B) hem de bilişsel yanlı süreçler yoluyla dolaylı olarak $(\mathrm{CxD})$ APD'yi etkilediği öne sürülmüştür. Yani, aktör kendi motivasyonlarını kullanarak, partner gerçekte anlayış, 


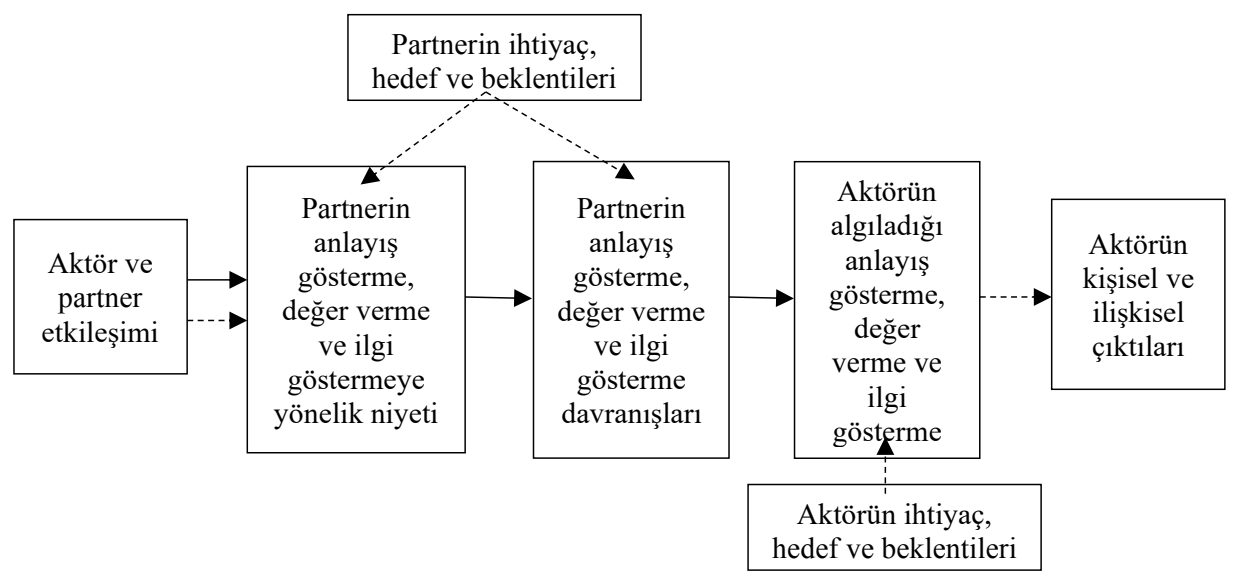

Not. Kesikli oklar kişisel süreçleri, düz oklar kişilerarası süreçleri ifade etmektedir.

Şekil 3. Duyarlık Modeli (Reis ve Gable, 2015).

değer verme veya ilgi gösterme davranışlarında bulunmadan da partneri duyarlı algılama potansiyeline sahip olabilmektedir. Modelde yer alan APD ile kişisel ve ilişkisel çıktılar arasındaki bağlantı (E) hali hazırda birçok çalışma tarafindan desteklenmektedir. Bu mekanizmaya göre, ilișkiyi sürdürme motivasyonu olan aktör partner duyarlığına dair olumlu yanlı değerlendirmelerde bulunmaktadır. Araştırmacılar modelde yer alan yanlı motivasyonların her koşulda APD'yi yükseltip yükseltmediğinin ve kişinin ruh halindeki veya ilişkideki günlük dalgalanmaların bu bağlantıyı etkileyip etkilemediğinin açıklığa kavuşturulması gerekliliğini vurgulamıştır.

Şekil 3 'te sunulan Reis ve Gable'ın (2015) önerdiği görece daha kapsamlı modelde ise partnerin duyarlığa yönelik niyeti ve asıl davranışı ayrı ayrı ele alınmıştır. Aktörün ve partnerin bireysel ihtiyaçları ve beklentilerinin ilişkiye dair geçmiş deneyimlerden etkilendiği önceki çalışmalarda vurgulanmıştır (Reis, 2014). Modele göre, duyarlık gerektiren herhangi bir olay yaşandığında öncelikle partner anlayış gösterme, değer verme ve ilgi göstermeye yönelik niyetini otomatik olarak etkin hale getirir. Daha sonra, tasarlanmış bu tepkiler aktöre sözel veya sözel olmayan yollarla aktarılır. Aktör partneri duyarlı algılayabilmek adına partnerin tepkilerinden ipuçları yakalamaya çalışır. APD'ye bağlı olarak da aktörün kişisel ve ilişkisel işlevleri şekillenir. Partnerin kendi ihtiyaç ve beklentileri niyetini ve duyarlık ifadelerini etkileyebilirken, aktörün ihtiyaç ve beklentileri de APD'yi doğrudan etkileyebilir. Aktör aşağıdaki dört ihtimalden biri gözlendiğinde partnerini duyarlı olarak algılamayabilir: 1) Partner yaşanan bir durumda duyarlık davranı-
Şında bulunması gerektiğini fark etmediğinde, 2) Partnerin duyarlı davranma yönünde bir niyeti olmadığında, 3) Partner ihtiyaç durumunda beklenen duyarlı davranışı gösteremediğinde, 4) Partnerin davranışı aktöre bağlı sebeplerle duyarlı olarak algılanamadığında.

Bu iki modelin örtüșen ve ayrıșan özellikleri bulunmaktadır. Her iki model de kişi içi ve kişilerarası süreçleri değerlendirmekle beraber, ilk model aktörün APD'ye olan duygusal ve bilişsel katkılarını vurgulamakta, ikinci model ise partnerin sürece dâhil ettiklerine odaklanmaktadır. Aynı zamanda modeller birbirini tamamlayan dinamikler de içermektedir. Dolayısıyla, ilk modelde yer alan aktörün partnere olan bağl1lığ 1 ve bilişsel yanlılığ1 ile ikinci modeldeki partnere özgü değişkenler eş zaman11 olarak test edilebilir. Modellerde önerilen değişkenler ve diğer çalışmalarda etkileri incelenen aktör ve partnerle ilişkili değişkenlerin yanı sıra APD'yi yordaması muhtemel yeni değişkenler de (örn., kültürel farklılıklar, kültüre bağlı cinsiyet rolleri, tepkisel-öngörüsel duyarlık, ilişkisel hareketlilik) resmin tamamını görebilmek adına göz önünde bulundurulmalıdır. APD sürecindeki olası rolü test edilebilecek değişkenlere sonuç ve tartışma bölümünde değinilecektir.

\section{Sonuç ve Tartışma}

Özet olarak, partneri duyarlı algılamanın hem psikolojik esenlik hem de sağlıklı bir romantik ilişkiye sahip olmak için önemli bir etken olduğunu söylemek mümkündür. APD yalnızca kişisel deneyimlerin ifade edildiği zamanlarda değil kişilerarası herhangi bir etki- 
leşimde de önem kazanabilmektedir. Yakın ilişki kuramları APD'nin güvenli ve güvenilir ilişkiler kurmak için APD'nin gerekliliğini vurgulamıştır. Kişinin partnerini ihtiyaç duyduğu anlarda duyarlı algılaması psikolojik ve fiziksel esenliğine ve başarıya ulaşma veya başarısızlı$\breve{g}$ 1 telafi etme gibi benlik düzenleme süreçlerine olumlu katkıda bulunmaktadır. Ayrıca APD yakınlık, güvenli hissetme, ilişkisel ilgi, cinsel ilgi ve affetme gibi ilişkilere özel duygu ve düşüncelerin ortaya çıkmasında önemli bir yere sahiptir. Kişiye ve partnerine özgü birçok değişken APD'yi artırabilmekte veya azaltabilmektedir. Kişinin kendi ihtiyaçları, hedefleri, arzuları, kișisel özellikleri, partnere bağlılığ1 ve partnere yönelik duyarlığı APD'yi şekillendirebilmektedir. Bunun yanında, partnerin ihtiyaçları, hedefleri, arzuları, duyarlık davranışları ve duyarlık göstermeye yönelik niyeti APD'nin düzeyini belirleyebilmektedir. Bu çerçevede, değerlendirilen tüm bulgular Reis'in (2007) APD'nin ilişki disiplinini düzenleyen anahtar bir ilke olduğu yönündeki görüşünü destekler niteliktedir.

Şimdiye dek, APD’nin varlığg ve gerekliliği birçok çalışma tarafından gösterilmiş, aktöre ve partnere bağl1 olası yordayıcıları tartışılmış olsa da APD'ye anlam katabilecek bazı noktaların hala açıklanmamış olduğunu söylemek mümkündür. Gelecek çalışmalarda, APD sürecindeki algısal farklılıkları anlamlandırmak adına kültürel temelli değişkenlerin yordayıcı etkisi göz önünde bulundurulmalıdır. Kendini açma davranışının kültürel olarak desteklenmediği, açık bir paylaşımda bulunmadan karşıdaki tarafından anlaşılmanın beklendiği toplumlarda, kendini açma sonrası gösterilmesi beklenen partner duyarlığının farklı bir yol izleyebileceği hesaba katılmalıdır. APD ile kişisel çıktılar arasındaki bağlantının bireyci (Amerika) kültürlerde, toplulukçu (Japonya) kültürlere göre daha güçlü bulunması (Taşfiliz ve ark., 2018) da bu konuda kültürel temelli çalışmaların yapılması gerekliliğini vurgulamaktadır. Aynı şekilde, kendini açma yazınının gözden geçirildiği bir çalışmada kendini açma davranışını tetikleyen ya da engelleyen arka plandaki unsurlar arasında kültür gösterilmektedir (Greene, Derlega ve Mathews, 2006). Bunun bir göstergesi olarak, Amerikalı ve Çinlilerin kendini açma açısından karşılaştırıldığı çalışmada, Amerikalıların kendilerini ilgi alanı, fikir, iş, ekonomik konular, bedene ve kişiliğe dair konularda Çinlilere göre ebeveynlerine, yabancılara, tanıdıklarına ve yakın arkadaşlarına daha fazla açtıkları belirtilmiştir (Chen, 1995). Ayrıca, ilişkilerin oluşum ve gelişme süreçlerindeki temel farklılıklar kültür ile açıklanabilmektedir. İlişkilerin oluşumu bireyci kültürlerde bireysel tercihlere toplulukçu kültürlerde ise toplumsal beklentilere göre gerçekleşmektedir. İlişkinin gelişim sürecinde bireyci toplumlarda partnerlerin birbirleriyle olan bağları ön plandayken toplulukçu toplumlarda önceden var olan yakın ilişki bağları ve ebeveyn gibi bağlanma figürleri varlığını ve işlevini sürdürmektedir. Dolayısıyla, kendini açmak ve kendini açmaya yönelik partnerin verdiği tepkileri değerlendirmek toplulukçu kültürlerde ilişkideki mutluluğu doğrudan tanımlayan bir mekanizma olmayabilir ya da başka mekanizmalara bağlı olarak işlev kazanıyor olabilir (Selçuk, Karagöbek ve Günaydın, 2018). Sessiz/sözsüz anlaşmanın işlevini sürdürdüğü ve dolayısıyla partnerlerin karşılıklı olarak "gözünden anlama" beklentisi içinde olduğu toplulukçu kültürlerde APD'nin var olabilmesi ve ilişkiye katkıda bulunabilmesi için partnerlerin öncelikle bu beklentiyi karşılaması gerekliliği akla gelmektedir. Bu durumda, o anki kişisel durumu ve duyguları kendisi dile getirmeden partneri tarafından anlaşılan kişi partnerini duyarlı olarak algılayabilir. Diğer yandan, kişiye kendisinin bir talebi olmadan yardım niyetiyle dahi olsa müdahale etmenin kişisel sınırları aşmak olarak algılandığ 1 toplumlarda, ancak duygu ve deneyimler partnere aktarıldıktan ve yardım ihtiyacı dile getirildikten sonra duyarlık göstermek yüksek APD düzeyi için daha doğru bir yaklaŞım olarak görülebilir. Bu anlamda yapılacak çalışmalar yalnızca bireyci veya toplulukçu toplumların bakış açısından sıyrılıp APD'nin yüksek ya da düşük düzeylerde olmasıla sonuçlanan süreçlerin kültürel uyum ve yap1larla nasıl ve ne derecede açıklanabileceğine odaklanmalidir. 


\section{Kaynaklar}

Adair, K. C., Boulton, A. J. ve Algoe, A. B. (2018). The effect of mindfulness on relationship satisfaction via perceived responsiveness: Findings from a dyadic study of heterosexual romantic partners. Mindfulness, 9, 597-609. doi: 10.1007/s12671-017-0801-3

Algoe, S. B. ve Zhaoyang, R. (2016). Positive psychology in context: Effects of expressing gratitude in ongoing relationships depend on perceptions of enactor responsiveness. The Journal of Positive Psychology, 11(4), 399-415. doi: 10.1080/17439760.2015.1117131

Bar-Kalifa, E., Bar-Kalifa, L., Rafaeli, E., George-Levi, S. ve Vilchinsky, N. (2016). Relational entitlement moderates the associations between support matching and perceived partner responsiveness. Journal of Research in Personality, 65, 1-10. doi: 10.1016/j.jrp.2016.08.009

Bar-Kalifa, E., Hen-Weissberg, A. ve Rafaeli, E. (2015). Perceived partner responsiveness mediates the association between social anxiety and relationship satisfaction in committed couples. Journal of Social and Clinical Psychology, 34(7), 587-610. doi: 10.1521/jscp.2015.34.7.587

Bar-Kalifa, E. ve Rafaeli, E. (2013). Disappointment's sting is greater than help's balm: Quasi-signal detection of daily support matching. Journal of Family Psychology, 27(6), 956-967. doi: 10.1037/ a0034905

Beck, L. A., Pietromonaco, P. R., DeVito, C. C., Powers, S. I. ve Boyle, A. M. (2014). Congruence Between Spouses' Perceptions and Observers' Ratings of Responsiveness: The Role of Attachment Avoidance. Personality and Social Psychology Bulletin, 40(2), 164-174. doi: 10.1177/0146167213507779

Berrios, R., Totterdell, P. ve Niven, K. (2015). Why do you make us feel good? Correlates and interpersonal consequences of affective presence in speed-dating. European Journal of Personality, 29, 72-82. doi: 10.1002/per.1944

Birnbaum, G. E., Ein-Dor, T., Reis, H. T. ve Segal, N. (2014). Why do men prefer nice women? Gender typicality mediates the effect of responsiveness on perceived attractiveness in initial acquaintanceships. Personality and Social Psychology Bulletin, 40(10), 1341-1353. doi: $10.1177 / 0146167214543879$.

Birnbaum, G. E. ve Reis, H. T. (2012). When does responsiveness pique sexual interest? Attachment and sexual desire in initial acquaintanceships. Personality and Social Psychology Bulletin, 38(7), 946-958. doi: 10.1177/0146167212441028
Birnbaum, G. E., Reis, H. T., Mizrahi, M., Kanat-Maymon, Y., Sass, O. ve Granovski-Milner, C. (2016). Intimately connected: The importance of partner responsiveness for experiencing sexual desire. Journal of Personality and Social Psychology, 111(4), 530-546. doi: 10.1037/pspi0000069

Bolger, N., Zuckerman, A. ve Kessler, R. C. (2000). Invisible support and adjustment to stress. Journal of Personality and Social Psychology, 79(6), 953961. doi: 10.1037//0022-3514.79.6.953

Canevello, A. ve Crocker, J. (2010). Creating good relationships: Responsiveness, relationship quality, and interpersonal goals. Journal of Personality and Social Psychology, 99(1), 78-106. doi: 10.1037/ a0018186

Caprariello, P. A. ve Reis, H. T. (2011). Perceived partner responsiveness minimizes defensive reactions to failure. Social Psychological and Personality Science, 2(4), 365-372. doi: 10.1177/1948550610391914

Chen, G. M. (1995). Differences in self-disclosure patterns among Americans versus Chinese: A comparative study. Journal of Cross-Cultural Psychology, 26(1), 84-91. doi: 10.1177/0022022195261006

Collins, N. L. ve Feeney, B. C. (2000). A safe haven: An attachment theory perspective on support seeking and caregiving in intimate relationships. Journal of Personality and Social Psychology, 78(6), 10531073. doi: 10.1037//0022-3514.78.6.1053

Cortes, K. ve Wood, J. V. (2018). Is it really "all in their heads"? How self-esteem predicts partner responsiveness. Journal of Personality, 86, 990-1002. doi: 10.1111/jopy. 12370

Debrot, A., Cook, W. L., Perrez, M. ve Horn, A. B. (2012). Deeds matter: daily enacted responsiveness and intimacy in couples' daily lives. Journal of Family Psychology, 26(4), 617-627. doi: 10.1037/a0028666

Deci, E. L. ve Ryan, R. M. (2000). The "what" and "why" of goal pursuits: Human needs and the self-determination of behavior. Psychological Inquiry, 11(4), 227-268. doi:10.1207/S15327965PLI1104_01

Derrick, J. L., Leonard, K. E. ve Homish, G. G. (2013). Perceived partner responsiveness predicts decreases in smoking during the first nine years of marriage. Nicotine \& Tobacco Research, 15(9), 15281536. doi:10.1093/ntr/ntt011

Fivecoat, H. C., Tomlinson, J. M., Aron, A. ve Caprariello, P. A. (2015). Partner support for individual self-expansion opportunities: Effects on relationship satisfaction in long-term couples. Journal of Social and Personal Relationships, 32(3), 368385. doi: 10.1177/0265407514533767 
Forest, A. L. ve Wood, J. V. (2011). When partner caring leads to sharing: Partner responsiveness increases expressivity, but only for individuals with low self-esteem. Journal of Experimental Social Psychology, 47(4), 843-848. doi: 10.1016/j. jesp.2011.03.005

Gable, S. L., Reis, H. T., Impett, E. A. ve Asher, E. R. (2004). What do you do when things go right? The intrapersonal and interpersonal benefits of sharing positive events. Journal of Personality and Social Psychology, 87(2), 228-245. doi: 10.1037/00223514.87.2.228

Gadassi, R., Bar-Nahum, L. E., Newhouse, S., Anderson, R., Heiman, J. R., Rafaeli, E. ve Janssen, E. (2016). Perceived partner responsiveness mediates the association between sexual and marital satisfaction: A daily diary study in newlywed couples. Archives of Sexual Behavior, 45(1), 109-120. doi: 10.1007/s10508-014-0448-2

Gordon, A. M. ve Chen, S. (2016). Do you get where I'm coming from?: Perceived understanding buffers against the negative impact of conflict on relationship satisfaction. Journal of Personality and Social Psychology, 110(2), 239-260. doi: 10.1037/ pspi0000039

Greene, K., Derlega, V. J. ve Mathews, A. (2006). Self-disclosure in personal relationships. A. L. Vangelisti ve D. Perlman (Ed.) The Cambridge Handbook of Personal Relationships içinde (409427). New York: Cambridge University Press.

Holmes, J. G. (2002). Interpersonal expectations as the building blocks of social cognition: An interdependence theory perspective. Personal Relationships, 9(1), 1-26. doi: 10.1111/1475-6811.00001

Ibarra-Rovillard, M. S. ve Kuiper, N. A. (2011). Social support and social negativity findings in depression: perceived responsiveness to basic psychological needs. Clinical Psychology Review, 31(3), 342-352. doi:10.1016/j.cpr.2011.01.005

Kane, H. S., McCall, C., Collins, N. L. ve Blascovich, J. (2012). Mere presence is not enough: Responsive support in a virtual world. Journal of Experimental Social Psychology, 48(1), 37-44. doi:10.1016/j. jesp.2011.07.001

La Guardia, J. G. ve Patrick, H. (2008). Self-Determination theory as a fundamental theory of close relationships. Canadian Psychology, 49(3), 201-209. doi: 10.1037/a0012760

Laurenceau, J. P., Barrett, L. F. ve Pietromonaco, P. R. (1998). Intimacy as an interpersonal process: The importance of self-disclosure, partner disclosure, and perceived partner responsiveness in interpersonal exchanges. Journal of Personality and Social
Psychology, 74(5), 1238-1251. doi: 10.1037//00223514.74.5.1238

Laurenceau, J. P., Barrett, L. F. ve Rovine, M. J. (2005). The interpersonal process model of intimacy in marriage: A daily-diary and multilevel modeling approach. Journal of Family Psychology, 19(2), 314-323. doi: 10.1037/0893-3200.19.2.314

Lemay Jr, E. P. (2014). Accuracy and bias in self-perceptions of responsive behavior: Implications for security in romantic relationships. Journal of Personality and Social Psychology, 107(4), 638-656. doi: $10.1037 / \mathrm{a} 0037298$

Lemay, E. P. ve Clark, M. S. (2015). Motivated cognition in relationships. Current Opinion in Psychology, 1, 72-75. doi:10.1016/j.copsyc.2014.11.002

Lemay Jr, E. P., Clark, M. S. ve Feeney, B. C. (2007). Projection of responsiveness to needs and the construction of satisfying communal relationships. Journal of Personality and Social Psychology, 92(5), 834-853. doi: 10.1037/0022-3514.92.5.834

Lemay Jr, E. P. ve Melville, M. C. (2014). Diminishing self-disclosure to maintain security in partners' care. Journal of Personality and Social Psychology, 106(1), 37-57. doi: 10.1037/a0034161

Lemay Jr, E. P. ve Neal, A. M. (2013). The wishful memory of interpersonal responsiveness. Journal of Personality and Social Psychology, 104(4), 653672. doi: 10.1037/a0030422

Lemay Jr, E. P. ve Neal, A. M. (2014). Accurate and biased perceptions of responsive support predict well-being. Motivation and Emotion, 38, 270-286. doi: 10.1007/s11031-013-9381-2

Maisel, N. C. ve Gable, S. L. (2009). The paradox of received social support: The importance of responsiveness. Psychological Science, 20(8), 928-932. doi: 10.1111/j.1467-9280.2009.02388.x

Maisel, N. C., Gable, S. L. ve Strachman, A. M. Y. (2008). Responsive behaviors in good times and in bad. Personal Relationships, 15(3), 317-338. doi: 10.1111/j.1475-6811.2008.00201.x

Mikulincer, M. ve Shaver, P. R. (2003). The attachment behavioral system in adulthood: Activation, psychodynamics, and interpersonal processes. $A d$ vances in Experimental Social Psychology, 35, 53152. doi: 10.1016/S0065-2601(03)01002-5

Murray, S. L., Holmes, J. G. ve Collins, N. L. (2006). The relational signature of felt security. Psychological Bulletin, 132(5), 641-666. doi: 10.1037/00332909.132.5.641

Pansera, C. ve La Guardia, J. (2012). The role of sincere amends and perceived partner responsiveness in forgiveness. Personal Relationships, 19(4), 696711. doi: 10.1111/j.1475-6811.2011.01386.x 
Reis, H. T. (2007). Steps toward the ripening of relationship science. Personal Relationships, 14(1), 1-23. doi: 10.1111/j.1475-6811.2006.00139.x

Reis, H. T. (2014). Responsiveness: Affective interdependence in close relationships. M. Mikulincer ve P. R. Shaver (Ed.), Mechanisms of Social Connections: From Brain to Groups içinde (255-271). Washington, DC: American Psychological Association.

Reis, H. T. ve Carmichael, C. (2006). Married spouses' experiences of intimacy and support. Yayımlanmamış metin.

Reis, H. T., Clark, M. S. ve Holmes, J. G. (2004). Perceived partner responsiveness as an organizing construct in the study of intimacy and closeness. D. J. Mashek ve A. Aron (Ed.), Handbook of Closeness and Intimacy içinde (201-225). Mahwah, NJ: Lawrence Erlbaum.

Reis, H. T., Crasta, D., Rogge, R. D., Maniaci, M. R. ve Carmichael, C. L. (2018). Perceived partner responsiveness scale (PPRS). D. L. Worthington ve G. D. Bodie (Ed.) The Sourcebook of Listening Research: Methodology and Measures içinde (516521). Hoboken, NJ : John Wiley \& Sons.

Reis, H. T. ve Gable, S. L. (2015). Responsiveness. Current Opinion in Psychology, 1, 67-71. doi:10.1016/j. copsyc.2015.01.001

Reis, H. T. ve Shaver, P. (1988). Intimacy as an interpersonal process. S. W. Duck (Ed.), Handbook of Personal Relationships içinde (367-389). Chichester, England: Wiley.

Segal, N. ve Fraley, R. C. (2016). Broadening the investment model: An intensive longitudinal study on attachment and perceived partner responsiveness in commitment dynamics. Journal of Social and Personal Relationships, 33(5), 581-599. doi: 10.1177/0265407515584493

Selçuk, E., Günaydın, G., Ong, A. D. ve Almeida, D. M. (2015). Does partner responsiveness predict hedonic and eudaimonic well-being? A 10-year longitudinal study. Journal of Marriage and Family, 78(2), 311-325. doi:10.1111/jomf.12272

Selçuk, E., Karagöbek, A. B. ve Günaydin, G. (2018). Responsiveness as a key predictor of happiness: Mechanisms and unanswered questions. M. Demir ve N. Sümer (Ed.) Close Relationships and Happiness across Cultures içinde (1-18). Dordrecht: Springer.

Selçuk, E. ve Ong, A. D. (2013). Perceived partner responsiveness moderates the association between received emotional support and all-cause mortality. Health Psychology, 32(2), 231-235. doi: 10.1037/ a0028276
Selçuk, E., Stanton, S. C., Slatcher, R. B. ve Ong, A. D. (2017). Perceived partner responsiveness predicts better sleep quality through lower anxiety. Social Psychological and Personality Science, 8(1), 8392. doi: 10.1177/1948550616662128

Shallcross, S. L., Howland, M., Bemis, J., Simpson, J. A. ve Frazier, P. (2011). Not "capitalizing" on social capitalization interactions: The role of attachment insecurity. Journal of Family Psychology, 25(1), 77-85. doi: 10.1037/a0021876

Slatcher, R. B., Selçuk, E. ve Ong, A. D. (2015). Perceived partner responsiveness predicts diurnal cortisol profiles 10 years later. Psychological Science, 26(7), 972-982. doi: 10.1177/0956797615575022

Spielmann, S. S., Maxwell, J. A., MacDonald, G. ve Baratta, P. L. (2013). Don't get your hopes up avoidantly attached individuals perceive lower social reward when there is potential for intimacy. Personality and Social Psychology Bulletin, 39(2), 219-236. doi: 10.1177/0146167212472541

Taşfiliz, D., Selçuk, E., Günaydın, G., Slatcher, R. B., Corriero, E. F. ve Ong, A. D. (2018). Patterns of perceived partner responsiveness and well-being in Japan and the United States. Journal of Family Psychology, 32(3), 355-365. doi: 10.1037/ fam 0000378

Tomlinson, J. M., Feeney, B. C. ve Van Vleet, M. (2016). A longitudinal investigation of relational catalyst support of goal strivings. The Journal of Positive Psychology, 11(3), 246-257. doi: 10.1080/17439760.2015.1048815

Winczewski, L. A., Bowen, J. D. ve Collins, N. L. (2016). Is empathic accuracy enough to facilitate responsive behavior in dyadic interaction? Distinguishing ability from motivation. Psychological Science, 27(3) 394-404. doi:10.1177/0956797615624491

Winterheld, H. A. ve Simpson, J. A. (2016). Regulatory focus and the interpersonal dynamics of romantic partners' personal goal discussions. Journal of Personality, 84(3), 277-290. doi: 10.1111/jopy.12158 


\section{Summary \\ Perceived Partner Responsiveness in Personal and Relational Contexts: A Review Study}

\author{
Fulya Kırımer-Aydınlı \\ Anadolu University
}

\author{
Nebi Sümer \\ Sabanc1 University
}

Perceived partner responsiveness (PPR) is one of the most functional factors contributing to one's personal well-being and close relationships. Partners are expected to be responsive in times of need. In fact, the interpretation of partner responsiveness determines the actual effect of responsiveness on their outcomes. Both parties sometimes need to be understood, validated, and cared by partner that makes PPR into a dyadic process. The purpose of the current paper is to present a comprehensive literature review about the role of PPR in personal context and romantic relationships. In the first section, the characteristics of PPR are defined and assessment methods are introduced. In the second section, the studies examining the role of PPR in intrapersonal and interpersonal processes are discussed and the models of PPR are presented. Finally, some recommendations are suggested for further studies.

\section{The Definition and the Importance of Perceived Partner Responsiveness \\ PPR is the evaluation process of partner's ${ }^{1}$ reac- tions as responsive or unresponsive in times of need. PPR depends on three major qualities, namely, sense of being understood, validated, and cared for by the partner (Reis, Clark, \& Holmes, 2004; Reis \& Shaver, 1988). More specifically, "feeling understood" refers to the be- lief that partners are aware of self-related characteristics. "Feeling validated" corresponds to the belief that part- ners respect personal desires and goals. "Feeling cared for" stands for the belief that partners help fulfill person- al and psychological needs (Reis, 2007). \\ The three major components of PPR were men- tioned first by Reis and Shaver's (1988) model of in- timacy process. They proposed that intimacy occurs depending on two factors: Personal self-disclosure and}

perceived partner responsiveness to that disclosure. Following the actor's sharing of personal experiences or feelings, the partner shows emotional or behavioral reactions. The actors' personal motives, needs, goals, and fears affect their personal disclosures and interpretations of partner reactions while the partners' motives, needs, goals, and fears form their own interpretations of disclosure and reactions to disclosure. Then, partner's reactions are assessed through the actor's sense of being understood, validated, and cared for, referring to PPR. Perceiving the partner to be responsive is expected to result in intimacy between partners. Since intimacy is a dyadic process, both dyads can take the actor or partner roles in time of disclosure. In this way, as reciprocal PPR increases, the mutual intimacy level also increases (Reis \& Shaver, 1988). In fact, intimacy is necessary to maintain relationship welfare and adaptive relations. Because self-disclosure and responsiveness exchange leads to a change in intimacy, the lack of one component automatically reduces intimacy. Importantly, unless having strong intimate bonds, relationships may result in dissatisfaction or even separation/divorce (Laurenceau, Barrett, \& Rovine, 2005). Therefore, it is necessary to understand the sequence of self-disclosure-responsiveness-PPR to establish intimate bonds and even to solve the reasons of disputes in a relationship.

\section{Measurement of PPR}

In the light of Reis and Shaver's (1988) pioneering article, the recent studies used many analogues scales directly measuring the major components of PPR (Reis, 2007). Most of the studies mentioned in the following sections have used this assessment method. Some of them have compared observer ratings and actor reports to detect, if any, perceptual differences.

1 It is critical to note that authors who conducted studies on this topic use various terms to describe the support-receiver (e.g., perceiver, actor, respondent) and support-provider (e.g., supporter, partner, responder). In this paper, "actor" was used referring to support-receiver/perceiver and "partner" was used referring to support-provider for ease of reading and avoiding potential confusion.

Address for Correspondence: Res. Asst. Dr. Fulya Kırımer-Aydınlı, Anadolu University, Faculty of Humanities, Department of Psychology, 26470, Tepebaş1 / Eskişehir

E-mail: fulyakirimer@anadolu.edu.tr 


\section{Intrapersonal and Interpersonal Outcomes of PPR}

Several theoretical approaches (e.g., attachment theory, interdependence theory, self-determination theory) support the main premises of PPR which are essential for maintaining personal and relational well-being. For instance, attachment theory suggests that people whose attachment figures are sensitive and responsive to their needs have stable and positive mental representations of self and others. However, when availability and responsiveness of attachment figures fail to satisfy the needs, the sense of insecurity increases and negative mental representations of self and others are activated (Mikulincer \& Shaver, 2003). In other words, an insecurely attached individual may perceive partner as unresponsive that may project negatively to emotion regulation processes.

\section{PPR and Psychological Well-Being}

It is presumable that partners provide people to feel better, and improve the quality of life. The positive contributions of PPR to psychological well-being (e.g., eudaimonic well-being; Selçuk, Günaydın, Ong, \& Almeida, 2015) and physical well-being (e.g., sleep quality; Selçuk, Stanton, Slatcher, \& Ong, 2017) have been demonstrated in the recent studies.

Lemay (2014) suggested that there are both accurate and biased perceptions influencing personal well-being through PPR. Supporting this argument, a recent study revealed that if the actor values the partner and if the partner acts responsively, then the actor tends to perceive the partner to be highly responsive, which in turn, enhances actor's well-being (Lemay \& Neal, 2014).

\section{PPR and Self-Regulation Processes}

The research findings showed that PPR influences and shapes self-regulation processes which are necessary to regulate defensiveness to failure (Caprariello \& Reis, 2011) and achieve personal goals (Tomlinson, Feeney, \& Van Vleet, 2016; Winterheld \& Simpson, 2016).

\section{PPR and Relationship Functioning}

A number of studies were conducted to clarify the role of PPR in relationship-specific mechanisms, such as intimacy (Laurenceau, Barrett, \& Pietromonaco, 1998), attractiveness (Berrios, Totterdell, \& Niven, 2015), sexual interest (Birnbaum, Reis, Mizrahi, Kanat-Maymon, Sass, \& Granovski-Milner, 2016), satisfaction (Algoe \& Zhaoyang, 2016), forgiveness (Pansera \& La Guardia, 2012), and affect regulation (Kane, McCall, Collins, \& Blascovich, 2012). Some of these findings have addressed the other interpersonal situations affecting PPR apart from self-disclosure (e.g., conflict, Gordon $\&$ Chen, 2016). In addition, the potential effects of the actor's personal characteristics on PPR, such as self-esteem (Forest \& Wood, 2011), social anxiety (Bar-Kalifa, Hen-Weissberg, \& Rafaeli, 2015), mindfulness (Adair, Boulton, \& Algoe, 2018), attachment dynamics (Beck, Pietromonaco, DeVito, Powers, \& Boyle, 2014), and gender roles (Laurenceau, Barrett, \& Rovine, 2005) have been investigated.

\section{Actor-Related and Partner-Related Dynamics in Predicting PPR}

Some researchers considered that there may be some other actor-related dynamics beyond personal characteristics moderating the effect of PPR on relationship functioning. For instance, supporting their proposed model of projection of responsiveness, Lemay, Clark, and Feeney (2007) found that PPR was predicted by the actor's own responsiveness more strongly than by the partner's actual responsiveness. This study is critical in terms of emphasizing the necessity of evaluating the potential effect of the actor's own behaviors and studying responsiveness in a dyadic framework. Lemay and Neal (2013) also found that the actor's value for partner (i.e., commitment, care, and regard) influences their memories about the partner's responsiveness and called this bias as wishful memory of responsiveness. The actor's daily sexual satisfaction was also found to predict PPR (Gadassi et al., 2015).

Partner-related factors also affect how actors interpret partner responsiveness. The influence of partner's empathy (Winczewski, Bowen, \& Collins, 2016) and actual responsive behaviors, as aforementioned, on PPR have been documented in the previous studies.

\section{Coping with Unresponsive Partner}

According to Lemay and Melville (2014), past studies disregarded the reverse effect of self-disclosure. People may avoid disclosing personal experiences with the partners if they behave in neglectful, antagonistic, or egocentric manners. If people disclose experiences which are not be reciprocated, there is a risk of rejection that decreases the trust in partner's care and commitment. Therefore, forecasting the outcomes of self-disclosure in unresponsive situations may prevent experiencing the negative consequences of partner unresponsiveness and may contribute to the relationship commitment. Experimental and daily-diary studies conducted among romantic couples supported this argument (Fivecoat, Tomlinson, Aron, \& Caprariello, 2015; Gable, Reis, Impett, \& Asher, 2004).

\section{Proposed Models of PPR}

Two specific models explaining the mechanisms of PPR have been recently proposed in the light of previ- 
ous findings. First, as a result of their studies on accurate and biased motivations of PPR, Lemay and Clark (2015) suggested that in addition to the partner's actual responsiveness, the actor's own feelings toward the partner affect PPR directly and indirectly through biased cognitive processes. Then, PPR increases relationship functioning and personal well-being. To this mechanism, the actor who is motivated to maintain the relationship tends to make positively biased evaluations about partner responsiveness.

Second, Reis and Gable (2015) distinguished the intentions and actual responsiveness of the partner. First, the partner activates his/her intentions to be responsive following a responsiveness-eliciting event is experienced. Then, the intentional responses are exhibited to the actor via verbal or nonverbal cues. The actor tries to find some clues from the partner's responses to perceive the partner to be responsive. In return, the actor's personal and relational functioning takes form depending on PPR. Whereas the partner's own needs and expectations may influence their intentions and expressions, the actor's own needs and expectations may have an impact on their PPR. The actor may not perceive the partner to be responsive if one of four possibilities is observed: (1) If the partner does not recognize the need for responsiveness in a situation, (2) if the partner does not have any intention to perform responsive acts, (3) if the partner cannot enact responsive behaviors as needed, or (4) if the partner's behaviors cannot be recognized as responsive by the actor.

There are both overlapping and distinguishing features of these two models. Although both models consider intrapersonal and interpersonal processes, the former model features the actor's role and the latter model features the partner's role in PPR. In fact, these two models capture complementary dynamics in the process of PPR. The actor's desire to bond and his/her cognitive biases should be converged with partner-specific variables of the second model and tested simultaneously. In addition to the actor- and partner-related variables whose effects were empirically tested, the role of unexplored third variables, such as cultural variations, culture-based gender roles, proactive-reactive sensitivity, and relational mobility, should be examined to better understand the dynamics of PPR in the future studies.

\section{Overview and Discussion}

Overall, it can be concluded that perceived partner responsiveness is critical for people to maintain a high quality of life as well as a functional and satisfactory romantic relationship. Perceiving partner to be highly responsive to one's needs makes positive contributions to the actor's psychological and physiological well-being, and self-regulation processes. PPR is also necessary to uncover many relationship-specific feelings, thoughts, and behaviors. Some actor-related and partner-related variables enhance or reduce PPR. In this framework, documented findings have largely corroborated Reis's (2007) argument that PPR is a key organizing principle of the relationship discipline.

Although a great number of studies have supported the functional role of PPR in intimate relationships, some actor- and partner-related predictors, which have not been explored yet could have effects in the paths to PPR. Future researchers should especially consider culture specific actor, partner, and relationship related characteristics to better understand the perceptual differences in the PPR process. For instance, in a society where disclosure behavior is not supported culturally and implicitly expressed needs are expected to be intervened PPR process might take a different trajectory. Supporting the need for cultural studies in this area, the researchers have found that the link between PPR and personal outcomes was stronger in individualist cultures (i.e., the United States) than collectivist cultures (i.e., Japan) (Taşfiliz, Selçuk, Günaydın, Slatcher, Corriero, \& Ong, 2018). Similarly, a review study, pointed out that culture is a factor triggering or preventing self-disclosure behavior (Greene, Derlega, \& Mathews, 2006). Confirming this argument, Chen's (1995) study showed that American partners disclose more in various topics as compared to their Chinese counterparts. Accordingly, cross-cultural studies should be conducted to investigate whether the underlying mechanisms of PPR are expressed with culture specific expectations. Anticipation of the needs that actor expressed tacitly might have a direct influence on the actor's interpretive filter of partner responsiveness in collectivist cultures. In contrast, responding the needs that actor expressed explicitly might more strongly predict higher levels of PPR. 